\title{
Development of a Gemstone Type Identification System Based on HSV Space Colour Using an Artificial Neural Network Back Propagation Algorithm
}

\author{
Ismatul Maula $^{a, *}$, Victor Amrizal ${ }^{b}$, Anif Hanifa Setianingrum ${ }^{c}$ and Nashrul Hakiem ${ }^{d}$ \\ a,b,c,d Department of Informatics, \\ Syarif Hidayatullah State Islamic University \\ J1. Ir. H. Juanda No 95 Ciputat 15412 \\ *Email: iismatull@gmail.com
}

\begin{abstract}
A gemstone is a mineral stone that be formed from the result of geological processes and has a hardness above 7 Mohs. Nowadays, gemstones have become famous in Indonesian society. Many facts concerning the business of gemstone rings, including encouragement by the the central government for the gemstone souvenirs that are given to State guests by the President of Indonesia, gemstone contests and gemstone exhibitions have all contributed to pique the interest of researchers in the subject. This current research is undertaken to create a system that is able to identify three kinds of gemstone, namely, Ruby, Sapphire and Emerald using the Hue Saturation Value (HSV) colour space, image processing techniques and an Artificial Neural Network (ANN) back propagation algorithm by learning from examples. The hue from the HSV colour space of a gemstone will be used by the system for training. In the image processing, the system will crop, resize, convert from RGB to HSV, obtain a Hue colour and extract the colour as a 30x3 matrix. The extracted result will be used to train an ANN consisting of three input layers, three hidden layers and one output layer with targets that have been pre-determined. The results of the tests showed a degree of accuracy of $90.66 \%$ with 5 times of training and 25 times of testing on any type of gemstone. The result shows that using Artificial Neural Network Back Propagation in identification gemstone types is success, because the accuracy system has a highest percentage.
\end{abstract}

Keywords: Image processing, Artificial Neural Network, back propagation, gemstone, HSV space colour.

\section{Introduction}

A natural gemstone is a mineral, stone, or organic matter that can be cut and polished or otherwise treated for use as jewellry or other ornament. A precious gemstone has beauty, durability, and rarity, whereas a semiprecious gemstone has only one or two of these qualities. A gem is a gemstone that has been cut and polished [1].

Indonesia has a great potential as a producer of precious stones, particularly diamond and varieties of semi-precious stones. The most famous source is located in South
Kalimantan, where many people are focused on the gemstone mining industry, particularly in Cempaka Village, $10 \mathrm{~km}$ from Martapura, the nearest major town, and $43 \mathrm{~km}$ southeast of Banjarmasin, the provincial capital. Besides Cempaka, there are some other five or six gemstone and diamond mining villages around the surrounding area [2].

In addition to gemstone rings, another potential use of gemstones is in souvenirs. According to Mr. Fikri, one of the sources interviewed in the course of this study, the rising prestige of gemstones is due to the assumptions made by the Indonesian society itself. The public observe the gemstone souvenirs given by the President to State guests who visit Indonesia, thus increasing the prestige of gemstones today.

Gemstones consist of various types that have high levels of hardness that varies between stone types. The hardness of stones is internationally measured using the Mohs scale created by Friedrich Mohs in 1812. The level of hardness of gemstones has a range of 7 to 10 on the Mohs scale, while a level of hardness below 7 Mohs include various kinds of precious stones. Generally, a higher Mohs scale reading means that the stone will have an expensive selling price. Any mineral, coloured or transparent, may be cut into a gemstone, but only minerals with a Mohs hardness above 6 are wearable and considered to be gemstones by the public [3].

According to [4], there are four characteristics that can be used to identify the type of gemstone based on physical aspects. These four are hardness, density, refraction of light and the colour of the mineral contained in the stone.

The gemstone phenomenon has become a trend in Indonesia and when taken with the facts mentioned above this caused the authors to be interested to perform research into gemstone type detection.

Current technology trends are fast-paced and development is making it easier to detect types of gemstone. One branch of technology is image processing. By taking existing Hue, Saturation and Value (HSV) colour in images of gemstone, the type of the gemstone can be detected through image processing. The colour or shine of a mineral gemstone can be detected through image processing technology. The Mineral gemstone colour is transformed into the HSV colour space to be easily processed. 
Identification object can be done by pattern recognition ([5], [6]), system learning ([7]-[12]) and fuzzy logic ([13], $[14])$. System learning is better then pattern recognition and fuzzy logic because system learning competent to adaptation and learning better in case environment change. This statement is in line with [14] that the writer user nonlinear parameters that have variant value to different operation condition. So system learning obtain to resolve complicated issue.

System learning have several methods, among which the most widely used are Back Propagation ([7], [8], [10], [14], [15]) and Multi Perceptron Layer ([16], [15], [17], [18]). Of the references that use both methods, the highest system accuracy value in classifying is held by Back Propagation with an average percentage value of 95\% [8]. While Multi Layer Perceptron has the highest average percentage value of $83.33 \%$ [19].

This research will use an image recognition method whereby a gemstone image is used as input to an image processing system. The image processing results will be analysed by performing image recognition into order to learn the characteristics of the Hue value of HSV colour space through employing an Artificial Neural Network (ANN) back propagation algorithm. After training, there will be a matching process to identify gemstone images by applying the ANN training results. The matching process will determine the type of gemstone [20].

\section{Related Work}

In related work, the authors did not find research that used a similar title but instead adopted some of the associated prior research as references. The first reference is by Adriano A. Mol and colleagues [21] researched the efficiency of gemstone cutting design for faceted gemstones in Brazil using an Artificial Neural Network. The cutting was based on the interaction of minor materials, the characteristics of materials and polyhedral shapes that are within gemstones. That process was developed to ensure that the hypotheses successfully utilises instrument class artificial intelligence and to open up the possibility of the development of CAD tools to increase the economic value when searching for a better cutting design for faceted gemstones. As yet, this reference is not supported by the Brazilian government.

The second reference is by Junhao Zou and Hyoungkwan Kim concerning the identification of the idle time of a hydraulic excavator in a construction site. Square images of the excavator were taken by using the HSV space colour [22]. The hue feature was used to distinguish the hydraulic excavator by the difference in colour whereas the saturation feature was used to differentiate the hydraulic excavator from the background that consisted of dark ground with white snow. A simple thresholding method used the hue and saturation features, along with a method of calculating the centroid point coordinates that allowed the system to produce accurate results for the excavator analysis. The results of this study indicate that the presented methodology has potential in promising applications for effective equipment management in construction projects. The training took about four seconds to process an image, so improving image processing efficiency will be an important step to bring the result of this research to fruition.

The next reference is by Ali Raza [9] who focused on the comparison of a Backpropagation method and a General Neural Network to detect submarine mines. The results showed that both techniques have good accuracy, but under some conditions, the Backpropagation method was better if the number of layers and neurons used was greater, while the Artificial Neural Network was better when using the default parameters that required less time during the bleaching and gaining stage. In similar research undertaken by Nimas Ayu Mailani [6] a study conducted to compare two methods of Artificial Neural Network Backpropagation and Learning Vector Quantisation (LVQ) in detecting Arabic letters. From this research, it was shown that the Backpropagation method has a higher accuracy than the LVQ method.

\section{Methodology}

In this section, will be show about research methodology, block diagram of the system, image processing workflow (pre-process), ANN training workflow and identification workflow.

1. Research Methodology

Below is a framework in this research:

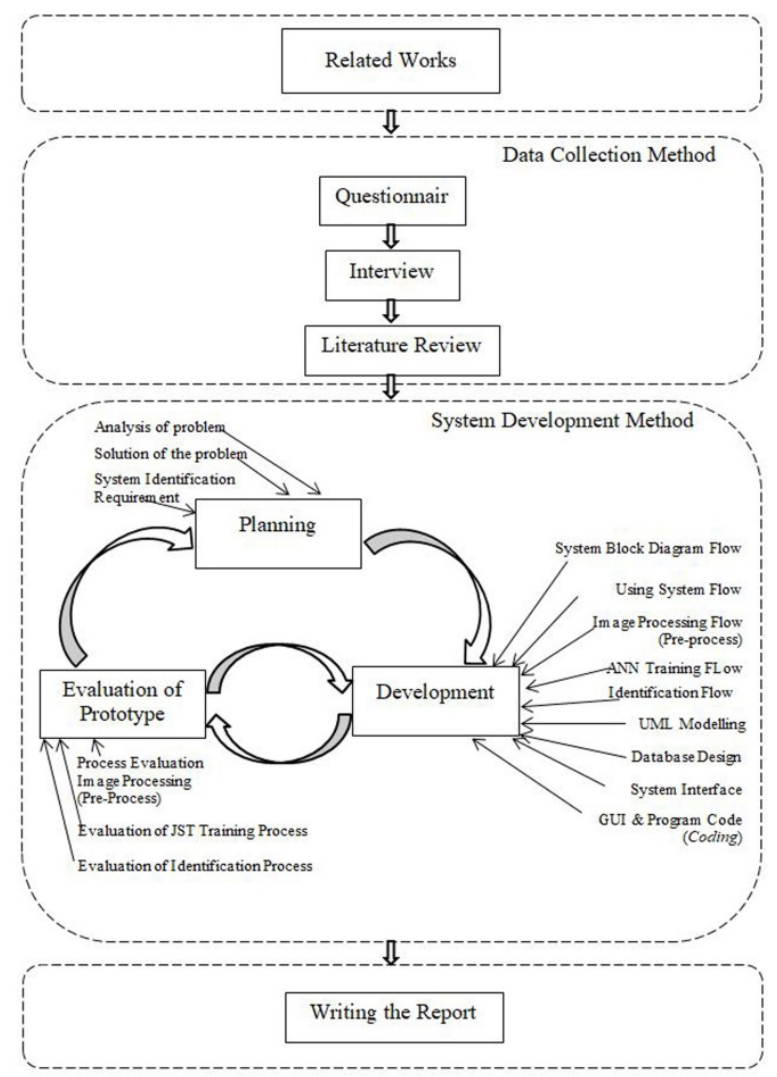

Fig. 1. Research Framework 
2. Block Diagram of System

The block diagram of the gemstone identification system can be seen in Figure 2.

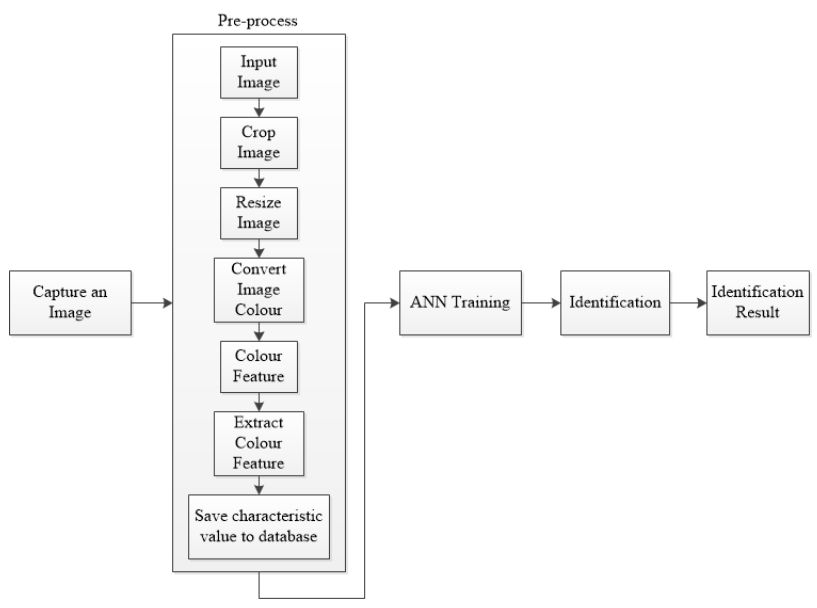

Fig. 2. Block Diagram of Gemstone Identification System

3. Image Processing Workflow (Pre-Process)

The image processing workflow of the gemstone identification system is shown in Figure 3.

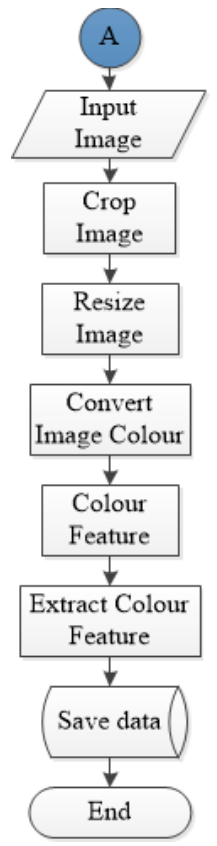

Fig. 3. Image Processing Workflow (Pre-Process)

4. ANN Training Workflow

The ANN training workflow of the gemstone identification system is shown in Figure 4.

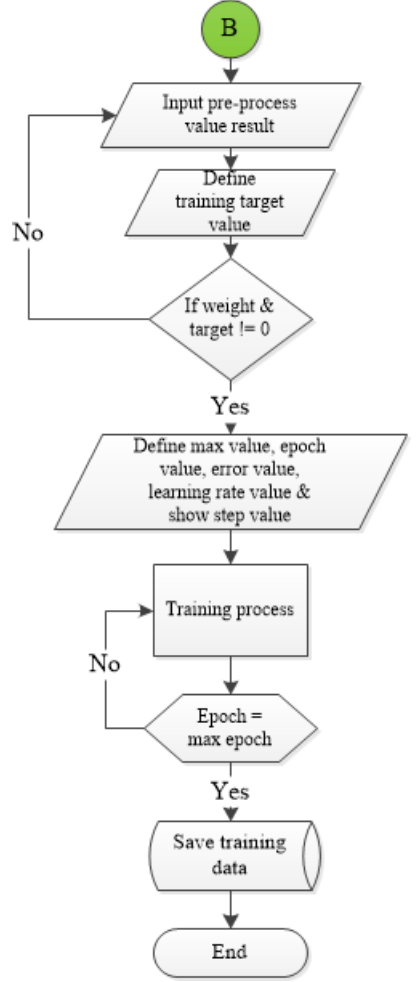

Fig. 4. ANN Training Workflow

5. Identification Workflow

The identification workflow of the gemstone identification system can view on Figure 5.

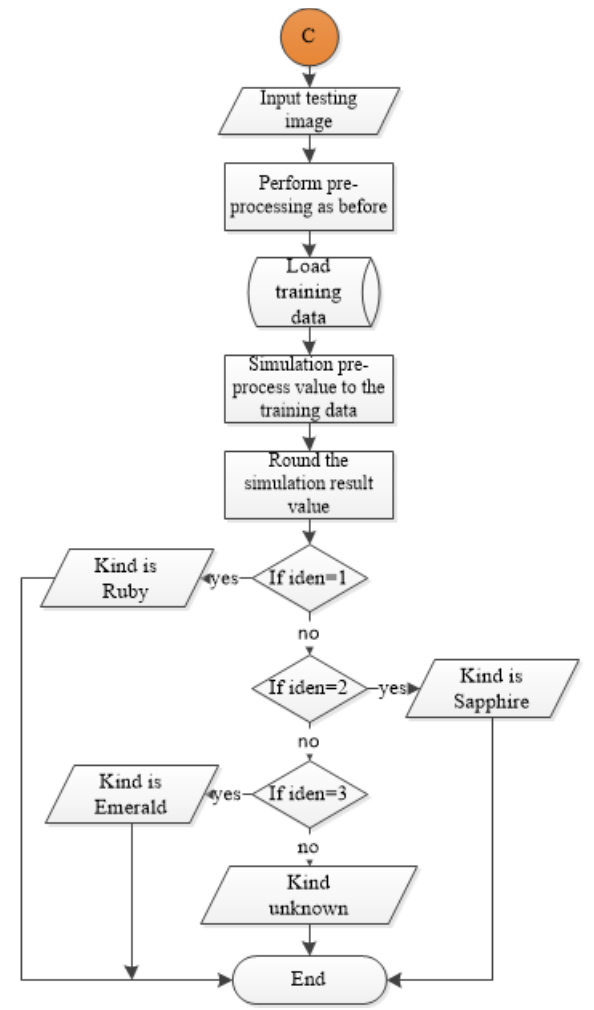

Fig. 5. Identification Workflow 


\section{Result and Discussion}

A. Gemstone Image

This research is use 30 images, 15 images to training and 15 others to testing. Each stone image was cropped in different positions. Each cropping will be performed to extract the colour feature in the image processing (preprocessing) stage that will generate the 30 colour feature characteristic values in the image. Figure 6 shows the gemstone images that will be identified.

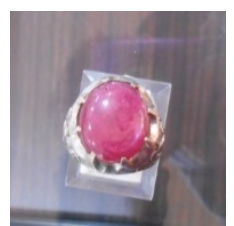

a. Sample of a Ruby

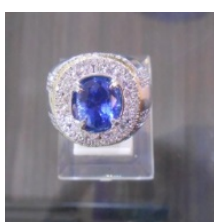

b. Sample of a Sapphire

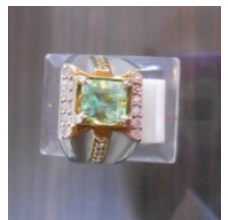

c. Sample of a Emerald

Fig. 6. Gemstone Examples

B. Characteristic of Gemstone Image

To obtain the characteristic value of any sample test, it is required to detect the hue colour in the HSV colour space in the entire matrix of existing images in the image processing step (pre-processing). The matrix produced as a result of the image processing (pre-processing) is mapped into a new matrix with dimensions $30 \times 1$.

The data is then compiled into a $30 \times 3$ matrix dimension representing the three types of gemstone to be identified. There are five databases with a $30 \times 3$ matrix dimension that will be trained by the ANN technique. One example of a database of gemstone images to be used for training can be viewed in Table 1.

Table 1. Data Extraction of 30x3 Matrix Dimension

\begin{tabular}{|l|l|l|}
\hline Ruby & Sapphire & Emerald \\
\hline 0.820 & 0.590 & 0.180 \\
\hline 0.840 & 0.590 & 0.310 \\
\hline 0.840 & 0.580 & 0.360 \\
\hline 0.840 & 0.590 & 0.370 \\
\hline 0.840 & 0.590 & 0.380 \\
\hline 0.840 & 0.590 & 0.270 \\
\hline 0.840 & 0.580 & 0.330 \\
\hline 0.840 & 0.590 & 0.370 \\
\hline 0.840 & 0.590 & 0.370 \\
\hline 0.840 & 0.590 & 0.360 \\
\hline 0.840 & 0.580 & 0.350 \\
\hline 0.840 & 0.580 & 0.350 \\
\hline
\end{tabular}

Table 2. Data Extraction of $30 x 3$ Matrix Dimension (Cont.)

\begin{tabular}{|l|l|l|}
\hline Ruby & Sapphire & Emerald \\
\hline 0.840 & 0.590 & 0.350 \\
\hline 0.840 & 0.590 & 0.270 \\
\hline 0.840 & 0.590 & 0.260 \\
\hline 0.840 & 0.590 & 0.310 \\
\hline 0.840 & 0.590 & 0.240 \\
\hline 0.840 & 0.590 & 0.260 \\
\hline 0.840 & 0.590 & 0.220 \\
\hline 0.840 & 0.600 & 0.310 \\
\hline 0.840 & 0.600 & 0.330 \\
\hline 0.840 & 0.580 & 0.230 \\
\hline 0.840 & 0.590 & 0.250 \\
\hline 0.840 & 0.580 & 0.230 \\
\hline 0.840 & 0.590 & 0.320 \\
\hline 0.830 & 0.590 & 0.330 \\
\hline 0.830 & 0.590 & 0.240 \\
\hline 0.840 & 0.590 & 0.230 \\
\hline 0.840 & 0.590 & 0.160 \\
\hline
\end{tabular}

C. Trial and Result

The system was tested using 30 sample images with 15 images to training and 15 images to identification with any of the 3 types of gemstone. The ANN training process begins with the input image, cropping the image, resizing the image, converting the colour image and extracting the colour features to obtain a $30 \times 1$ matrix. Then the matrix is compiled into a $30 \times 3$ matrix dimension representing the three types of gemstone and this is saved into a database. The output after training is in the form of a network shaped $3 \times 1$ array that is used as a target in the ANN training. That matrix will also be used as a target during the identification process.

The identification process begins with image processing. In this step, the weights do not match with the target. This identification is based on a target that was obtained in the ANN training process. The target is used as a parameter to determine the type of gemstone that uses the characteristics of the image such as the result of the colour feature extraction of the Hue colour. The identification result can be seen in Figure 7.

identifikasi

\section{IDENTIFICATION}

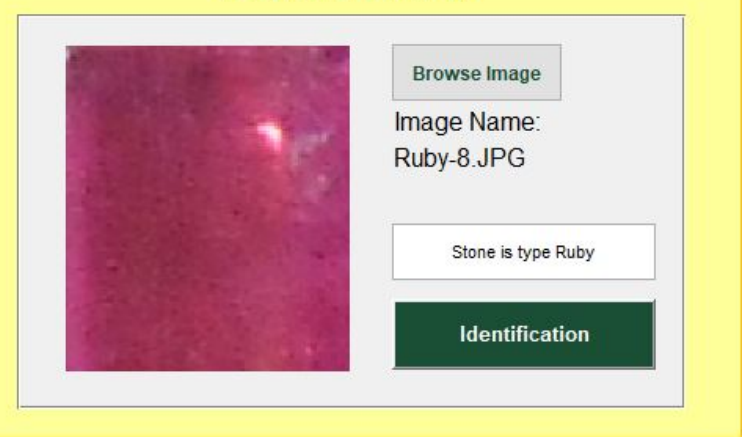

Fig. 7. Result of Identification During Trial Process 


\section{Analysis of Trial Result}

After testing samples of identification of gemstone image, it can be obtained a result which indicates that analysis and identification method of gemstone image using image processing and ANN have an average accuracy of $90.66 \%$. Summary of the test result of all three types of gemstone can be seen in table 2 below.

Table 3. Accuracy Rate of the Test Result

\begin{tabular}{|l|l|}
\hline Types of Gemstone & Percentage (\%) \\
\hline Ruby & $100 \%$ \\
\hline Sapphire & $96 \%$ \\
\hline Emerald & $76 \%$ \\
\hline The percentage rate & $90,66 \%$ \\
\hline
\end{tabular}

The summary result in Table 2 shows the rate percentage indicates a high accuracy at $90.66 \%$ with different variations. The table shows that Emeralds have the least accuracy when compared with the other types of gemstone. This is caused by several factors, including:

1. Image Capture Influence

When a sample is exposed to image capture, there will be a high level of brightness. Thus, the colour values in the image will be different from when the sample was not exposed to bright light.

Ideally, the same room lighting is required during image capture. In this research, bright lighting is required, which is performed in a closed room lit by a lamp. This is generally acceptable because the same lighting is used on all the samples to produce uniformity in the value extraction from the image.

2. Image Processing (Pre-Processing) Influence Cropping the image may not focus correctly on the gemstone area meaning that the training process will produce output that is less accurate when the system is used in the identification process.

Resizing the image in the pre-processing and identification process will determine the accuracy of the system. If a larger image size is used this will cause the computing time of system to be longer. However, if the image size is too small, then the HSV value would be worth little. Hence, it is necessary to resize the image so that the scale is not too big nor too small. Scale resize used in this research is 0.25 .

The colour feature extraction used determines the level of accuracy of the system. Functional rounding of two decimal places behind the decimal point determines the value of the image characteristics. If the value of the rounding used is too close to the tolerance level, especially if there is a large tolerance, then this would cause the identification to be inexact.

3. Matrix Value Extraction Result Influence

Value extraction with a large range will have a detrimental effect when simulating in the network. Example characteristic value ranges can be viewed in Table 3. The table shows the three stone ranges identified.
Table 4. Characteristic Value Ranges of Gemstone

\begin{tabular}{|l|l|}
\hline $\begin{array}{l}\text { Types of } \\
\text { Gemstone }\end{array}$ & $\begin{array}{l}\text { Characteristic } \\
\text { Value Range }\end{array}$ \\
\hline Ruby & $0.82-0.84$ \\
\hline Sapphire & $0.58-0.6$ \\
\hline Emerald & $0.16-0.38$ \\
\hline
\end{tabular}

The characteristic values for the Emerald are seen as having a range that is too large compared to the Ruby and Sapphire. This will affect the identification because during the simulation process the range of characteristic values is so large so the rounding value does not match the values in the database.

\section{Size of Input Matrix Influence}

It was determined that the $30 \times 3$ matrix identification result was better than the $15 \times 3$ matrix and the $60 \times 3$ matrix. The following summary in Table 4 gives the percentage accuracy of trials with a $15 \times 3$ matrix and a $60 \times 3$ matrix over 25 test runs:

Table 5. Accuracy Level Trial Result for 15x3 Matrix and 60x3 Matrix

\begin{tabular}{|l|l|l|}
\hline $\begin{array}{l}\text { Types of } \\
\text { Gemstone }\end{array}$ & $\begin{array}{l}\mathbf{1 5 x 3} \\
\text { Matrix (\%) }\end{array}$ & $\begin{array}{l}\mathbf{6 0 x 3} \\
\text { Matrix (\%) }\end{array}$ \\
\hline Ruby & $96 \%$ & $36 \%$ \\
\hline Sapphire & $88 \%$ & $32 \%$ \\
\hline Emerald & $60 \%$ & $64 \%$ \\
\hline Rates & $\mathbf{8 1 . 3 3 \%}$ & $\mathbf{4 4 \%}$ \\
\hline
\end{tabular}

This is because the ANN method has a characteristic in which a more detailed characteristic of the image will produce a worse mean squared error (MSE). This is especially true in this research with an epoch amount of 2000. So when the training MSE declines, this is affected by the amount of characteristics within an image. The MSE values for the first sample are given in Table 5.

Table 6. MSE Value for $15 \times 3,30 \times 3$ and 60x3 Matricies

\begin{tabular}{|l|l|}
\hline $\begin{array}{l}\text { Dimensions of } \\
\text { Matrix }\end{array}$ & MSE Value \\
\hline $15 \times 3$ Matrix & 0.00150000 \\
\hline $30 \times 3$ Matrix & 0.00091036 \\
\hline $60 \times 3$ Matrix & 0.01070000 \\
\hline
\end{tabular}

From that table it can be seen that the smallest MSE value is for the $30 \times 3$ matrix. Therefore, the best accuracy is for the system using an input size of a $30 \times 3$ matrix. Figure 8 shows a graph of training performance for the $30 \times 3$ matrix: 


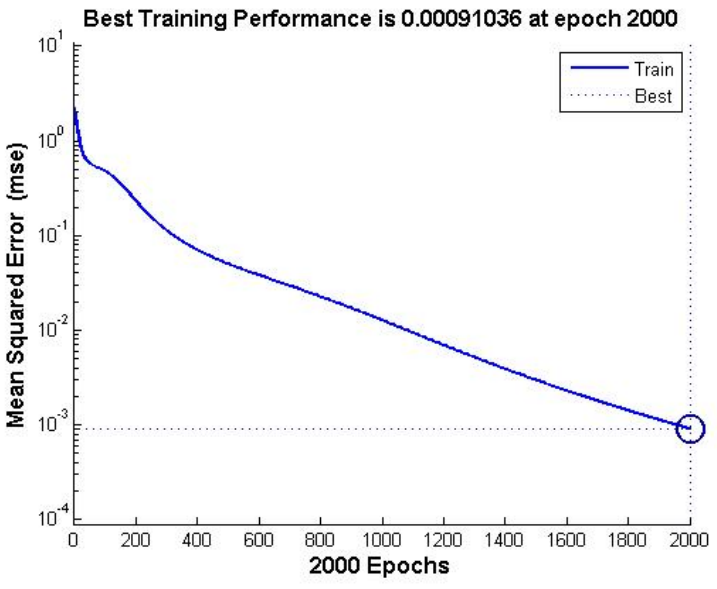

Fig. 8. Graph of Training the ANN with a 30x3 Matrix

\section{Conclusion}

This paper presented an image processing and Artificial Neural Network technique to identification three type of gemstones by taking the Hue value on the image. The best accuracy of the system had shown by $30 \times 3$ matrix then $15 \times 3$ metrix and $60 \times 3$ matrix dimensions. The choice of matrix dimension that used in training ANN affects the optimal training and high the accuration of system. This system can not totally use to identify all of the type of gemstone if just use Hue value of the image as the parameter. In the fact one gemstone have many varian colour, for example Ruby. In addition to the reb Ruby alse has a bright blue color. Depending on the amount of chromium content. So more study is recommended to use others parameters of the gemstone to identification its. Also is recommended to develop this system in mobile environment. It can easier the user that want to identification their gemstone own in everywhere without open their personal computer on the desktop.

Based on the result of training and analysis found that Back Propagation algorithm is a good alternative to identify gemstone type. The results of the tests showed a degree of accuracy of $90.66 \%$ with 5 times of training and 25 times of testing on any type of gemstone. In the future, compare this result with others algorithm in Artificial Neural Network to know which the best algorithm in identification gemstone type.

\section{Reference}

[1] S. I. Gemstones of America, "Natural Gemstones," M. Amethyst crystals, Ed. United States: Quartz, Rhode Island, 2000.

[2] M. of T. of T. R. of Indonesia, "Indonesian Gemstones Exclusively Captivating," in Trade Research and Development Agency Ministry of Trade, Republic of Indonesia, Indonesia: Trade Research and Development Agency Ministry of Trade, Republic of Indonesia, 2010.

[3] B. Grobéty, "Colored Gemstones," Switzerland: Universitas Friburgensis, 2012.

[4] H. M. Dr. Tobias Häger, Dr. Michael Priester, Dr. Mahinda S. Rupasinghe and U. S. M. and I. ITC, Projek Consult, "INFORMATION AND SOURCE MATERIAL ON GEMSTONE IDENTIFICATION AND VALUATION," in
Best Practice in Small-Scale Gemstone Mining, Sri Lanka, 2003.

[5] A. P. B. Moghaddam, T. Jebara, "Bayesian Face Recognition, Pattern Recognition," vol. Vol. 33, no. Issue 11.

[6] N. H. Nimas Ayu Mailani, Victor Amrizal, "Comparative Analysis of the Accuracy of Backpropagation and Learning Vector Quantisation for Pattern Recognition of Hijaiyah Letters," 2016 6th Int. Conf. Inf. Commun. Technol. Muslim World 978-1-5090-4521-1/16 \$31.00 (C) 2016 IEEE 3162016 6th Int. Conf. Inf. Commun. Technol. Muslim World, 2016.

[7] L. Y. Yang Fei, Gao Pengdong, "Evolving Resilient BackPropagation Algorithm for Energy Efficiency Problem," MATEC Web Conf. 770 7, 2016.

[8] G. de J. G.-B. Jesús Salvador Velázquez-González, Alberto Jorge Rosales-Silva, Francisco Javier Gallegos-Funes, "Detection and classification of Non-Proliferative Diabetic Retinopathy using a Back-Propagation neural network," Sci. Inf. Syst. Netw. Sci. Journals from Lat. Am. Caribbean, Spain Port. Non-profit Acad. Proj. Dev. under open access Initiat., 2015.

[9] A. Z. Ali Raza, M. Umair Khalid, "Comparison between Backpropagation and General Regression Neural Networks for Underwater Mine detection," Proc. Int. Bhurban Conf. Appl. Sci. Technol. Islam. Pakistan, January, 2011.

[10] A. W. W. N. Farida Asriani, "Bar Features Extraction for Handwritten Account Number Recognition with Backpropagation Neural Networks," Din. Rekayasa, vol. Vol. 8 No., 2012.

[11] and A. Ghaedi, Parichehr Harounabadi, "Identifying spam email messages using an intelligence algorithm," Decis. Sci. Lett., 2014.

[12] H. C. Qian Wang, Boyan Cai, Yajie Yu, "Spectral Quantitative Analysis Model with Combining Wavelength Selection and Topology Structure Optimization," J. Spectrosc., vol. 2016, p. 12 Pages, 2016.

[13] M. Tiwari, "A Review of Detection and Tracking of Object from Image and Video Sequences," Int. J. Comput. Intell. Res., vol. Volume 13, 2017.

[14] G. A. Nebojša Ralević, Nataša Glišović, Vladimir Đaković, "Hybrid System Prediction for the Stock Market: The Case of Transitional Markets," Industrija, vol. Vol.45, 2017.

[15] D. D. Mawloud GUERMOUI, Abdelaziz RABEHI, Said BENKACIALI, "Daily global solar radiation modelling using multi-layer perceptron neural networks in semi-arid region."

[16] D. B. S. Diana Wisnu Wardani, Projo Danoedoro, "Kajian Perubahan Penggunaan Lahan Berbasis Citra Satelit Penginderaan Jauh Resolusi Menengah Dengan Metode Multi Layer Perceptron Dan Markov chain."

[17] H. and O. A. Iglesias, Carla Santos, António José Alves Martínez, Javier Pereira, "Influence of Heartwood on Wood Density and Pulp Properties Explained by Machine Learning Techniques," Forests, 2017.

[18] H. R. Noraina Mazuin Sapuan, Suzaida Bakar, "PREDICTING THE PERFORMANCE AND SURVIVAL OF ISLAMIC BANKS IN MALAYSIA TO ACHIEVE GROWTH SUSTAINABILITY," SHS Web Conf., 2017.

[19] A. S. dan R. Ediati, "Identifikasi Kematangan Buah Tropika Berbasis Sistem Penciuman Elektronik Menggunakan Deret Sensor Gas Semikonduktor Dengan Metode Jaringan Syaraf Tiruan."

[20] J. J. Siang, Jaringan Syaraf Tiruan Dan Pemrogramannya Menggunakan Matlab. Yogyakarta: Andi Offset, 2009.

[21] R. R. Mol, Adriano A., A Martins-Filho, Luiz S., Jose' Demisio S. da Silva, "E ciency parameters estimation in gemstones cut design using artificial neural networks," Comput. Mater. Sci. $38,2005$.

[22] K. H. Zou Junhao, "Using Hue, Saturation, and Value Color Space for Hydraulic Excavator Idle Time Analysis," New York Univ., 2007. 